\title{
Fronteiras em Movimento: o Oeste nos Estados Unidos e no Brasil
}

\author{
Fronteras en Movimiento: o Oeste en Estados Unidos y no Brasil \\ Movement Frontiers: The West in the United States and the Brazil
}

\author{
Ms. Wagner Henrique Neres Fiuza ${ }^{1}$ \\ Dra. Beatriz Anselmo Olinto 2
}

\begin{abstract}
Resumo
A construção de estados nacionais na América pode ser visualizada por distintos movimentos políticos, culturais e socioeconômicos. Diferentes intelectuais, em diferentes países, buscaram formulações teóricas para explicar seu passado e ensejar políticas de territorialização e legitimação do nacional. Neste sentido, o texto compara o conceito de fronteira aberta, desenvolvido por Frederick Jackson Turner em 1893, ao conceito de fronteiras guaranis de José de Melo e Silva, publicado em 1939. Entende-se que conceitos podem ser apropriados em contextos geográficos e temporais diferentes, resultando em propostas diferenciadas da construção de identidades nacionais e representações de fronteira. Entende-se que demarcar fronteiras significa estabelecer representações do outro e erigir regiões. Neste caso, tanto os Estados Unidos rumo ao Pacífico quanto o Brasil nação em relação ao país vizinho Paraguai, em que Melo e Silva buscava combater a fronteira aberta e demarcala na construção da brasilidade em oposição ao outro indígena sul-americano. Tais fronteiras desvelam relações de poder que instauram processos de crença e di-visão do mundo social.
\end{abstract}

Palavras-Chave: José de Melo e Silva, Fronteiras Guaranis, Brasil, Paraguai, Frederick Jackson Turner.

\section{Resumen}

La construcción de los estados nacionales en América puede ser visto por diferentes movimientos políticos, culturales y socioeconómicos. Intelectuales diferentes en diferentes países, buscaron formulaciones teóricas para explicar su pasado y la territorialización y la legitimidad de las políticas nacionales. En este sentido, el texto compara el concepto de fronteras abiertas, desarrollado por Frederick Jackson Turner en 1893, y el concepto de frontera Guaraní del José de Melo e Silva, publicado en 1939. Se entiende que los conceptos pueden ser apropiados en contextos geográficos y de tiempo diferente resultando en diferenciada propuso la construcción de las identidades nacionales y representaciones de frontera. Se entiende que demarcar las fronteras significa establecer representaciones del otro y erigir regiones. En este caso, tanto en los Estados Unidos en la búsqueda por el Pacífico como Brasil en relación con el país vecino Paraguay, donde Melo Silva y trataron de combatir la frontera abierta y lo marca en la construcción de brasilidad a diferencia del otro: los indígenas sudamericanos. Tales limites revelan las relaciones de poder que establecen los procesos de creencias y di-visión del mundo social.

Palabras claves: José de Melo y Silva, Fronteiras Guaranis, Brasil, Paraguay, Frederick Jackson Turner.

\begin{abstract}
The construction of national states in America can be visualized by distinct political, cultural and socioeconomic movements. Different intellectuals, in different countries, sought theoretical formulations to explain their past and to induce policies of territorialization and legitimation of the national. In this sense, the text compares the concept of the open frontier developed by Frederick Jackson Turner in 1893 to the concept of the Guaraní

\footnotetext{
${ }^{1}$ Mestre em História e Regiões; Secretaria Estadual de Educação do Paraná (SEED), Guarapuava, Paraná, Brasil; wagnerunicentro@ hotmail.com. Trabalho apresentado no I Seminário Latino-Americano de Estudos em Cultura - SEMLACult, Foz do Iguaçu/PR, Brasil, 2017.

${ }^{2}$ Doutora; Professora Associado no Departamento de História da UNICENTRO; Guarapuava, Paraná, Brasil; biaolinto@hotmail.com
} 
frontiers of José de Melo e Silva, published in 1939. It is understood that concepts may be appropriate in different geographic and temporal contexts, Resulting in differentiated proposals for the construction of national identities and border representations. It is understood that demarcating borders means establishing representations of the other and erecting regions. In this case, both the United States moved to the Pacific and Brazil nation to the neighboring Paraguay, where Melo e Silva sought to combat the open frontier and demarcated it in the construction of Brazilian as opposed to the other South American indigenous. These frontiers reveal relationships of power that establish processes of belief and dis-vision of the social world.

Key Words: Key words: José de Melo and Silva, Guaraní Frontiers, Brazil, Paraguay, Frederick Jackson Turner

\section{Introdução}

A construção dos estados nacionais americanos está calcada nos movimentos de independência a partir do século XVIII. Tais movimentos contaram com apoio e formulação de teóricos que projetavam suas nações nos escritos e impressos, no sentido proposto por Benedict Anderson. Assim, pode-se dizer que tais ideias se projetavam sobre terras ainda imaginárias suas comunidades imaginadas, territorializando-as com mapas, cartas, relatos, e mesmo em jornais e romances. Isso implica também uma comunidade (imaginada) de leitores, construída simultaneamente à própria consciência nacional ou consciência de outros-como-eu ou outros-como-nós (ANDERSON, 2008, p. 56).

Nessa demarcação do nós constroem-se relações de diferença com os outros. E essas relações podem ser percebidas enquanto práticas de poder na definição de identidades, afinal "todas as práticas de significação que produzem significados envolvem relações de poder, incluindo o poder para definir quem é incluído e quem é excluído" (WOODWARD, 2000, p. 18). Tais práticas de poder estão relacionadas à própria constituição dos estados nacionais via demarcação de seus limites, forjando regiões de poder. Como um conceito,

(...) a região é espaço de luta, é fruto de uma conquista, fronteiras nascidas da implantação de um governo, de uma dominação. A região é fruto de operações estratégicas, políticas, administrativas, fiscais e militares. As regiões nascem, na antiguidade, à sombra dos exércitos" (ALBUQUERQUE JR, 2008, p. 56-57).

Sendo assim, estabelecer os limites de um estado nação significa também produzir discursos de diferença, sobre si, sobre os outros, com intentos "de dar a conhecer e de fazer reconhecer, de impor a definição legítima das divisões do mundo social e, por este meio, de fazer e de desfazer os grupos" (BOURDIEU, 2010, p. 113). Neste sentido, segue-se apontamentos acerca de dois conceitos de fronteira que relacionavam a construção de identidades nacionais na América. O primeiro consta no texto "The Significance of Frontier in American History", foi publicado por Frederick Jackson Turner nos Estados Unidos em 1893. 
O segundo, "Fronteiras Guaranis", foi publicado por José de Melo e Silva, no Brasil, em 1939.

\section{A Fronteira Aberta}

No ano de 1893, o historiador Frederick Jackson Turner (1861-1932) passou a publicar sobre a frontier thesis, na qual a ideia de Great West ou Grande Oeste estava calcada na concepção de nacionalismo e democracia norte-americana. Após a Guerra da Secessão (1861-1865), houve condições de possibilidade nas décadas seguintes para um discurso de união, otimista e relacionado ao progresso daquela sociedade. E as palavras do então jovem Turner, que cresceu no ambiente daquela reconstrução, ocuparam essa função voltando seus olhos para o Oeste e para o passado.

Segundo ele "The existence of an area of free land, its continuous recession, and the advance of American settlement westward, explain American development" (TURNER, 1893, p. 1). Assim, a existência das free lands como terras livres era inversamente proporcional à presença norte-americana no westward, pois estar no ocidente significava o próprio desenvolvimento norte-americano. Ideias como essa foram condensadas em um paper lido na reunião da America Historical Association, em Chicago, aos 12 dias de Julho de 1893. Elas buscavam defender a importância do Oeste frente à costa Atlântica, afinal, para ele "The true point of view in the history of this nation is not the Atlantic coast, it is the Great West" (TURNER, 1893, p. 2).

No decorrer de sua carreira, Turner desenvolveu essas ideias em diversos outros textos, até meados da década de 1910. Para Ávila (2005), na composição destes textos, o Great West de Turner também representava os valores fundamentais da economia e sociedade estadunidense, tais como o individualismo e a democracia. Com a frontier thesis, Turner conseguiu atuar em duas frentes, ou seja, não só "explicar o desenvolvimento da história dos Estados Unidos em uma linguagem científica", mas também "criou um verdadeiro épico para a origem da nação, transferindo a ação dos grandes personagens históricos para a os milhares de anônimos que ajudaram a construir a democracia americana” (AVILA, 2005, p. 192).

Turner valoriza em sua narrativa a construção daquele Oeste por milhares de anônimos homens e mulheres que migraram para aquele lugar, considerando-os verdadeiros founding fathers da nação norte-americana (ÁVILA, 2005, p. 193). Neste sentido, não é o Estado o grande propulsor para o Oeste, mas sim a nação, composta por inciativas individuais que tinham um sonho em comum: Great West. Qual seria então o fator de união entre essas 
pessoas? Talvez, a resposta de Turner esteja em uma fala citada por ele de Lyman Beecher (1835): "Let no man at the East quiet himself and dream of liberty, whatever may become of the West.... Her destiny is our destiny” (TURNER, 1893, p. 15). Em outras palavras, o destino da nação era o mesmo, para todos os sonhos de Liberdade, para todos os homens do Leste, para todos "nós" norte-americanos.

Reforçar a ideia de destino de uma nação era importante pois, segundo ele, muito estava sendo escrito sobre a fronteira enquanto uma warfare border, baseada no conflito e na guerra. Propunha que, para além disso, ela deveria ser estudada também pelo viés da história e da economia. No aspecto do conflito, a fronteira indígena era perigosa, construída por aqueles que estavam do lado de lá, e que deveria ser transformada em nossa, pela conquista. Isso porque, se "the Indian was a common danger, demanding united action" (TURNER, 1893, p. 6). O perigo da fronteira indígena teria sido, portanto, um fator delimitador de união para que aquele movimento não cessasse, e esta era a história de desenvolvimento norte-americano que deveria ser contada. Sob a pressão de franceses e de ingleses, entre a figura do Trader e do Farmer, do comércio e das plantações, a civilização teria se espalhado por aquelas terras rumo ao Oeste (TURNER, 1893, p. 6).

Além de iniciativas individuais aquele mesmo Oeste também era o princípio e a finalidade da expansão das instituições norte-americanas, afinal: "The growth of nationalism and the evolution of American political institutions were dependent on the advance of the frontier..." (TURNER, 1893, p. 5). Dentre elas, algumas áreas estavam especialmente relacionadas à fronteira: "The most effective efforts of the East to regulate the frontier came through its educational and religious activity" (Turner, 1893, p. 15). A presença de atividades educacionais e religiosas, comandada a partir do Leste, denotava a percepção de que lá se realizaria o progresso espiritual e material do homem. Essa característica formaria o homem americano por excelência. Aquela fronteira estaria, portanto, permeada pelo perigo indígena, aberta e em movimento - tanto sobre terras indígenas quanto para o futuro.

Como professor na Universidade de Wisconsin e mais tarde em Harvard, as teses de Turner se popularizaram na academia norte-americana. Após décadas de uma forte influência nos departamentos de história dos Estados Unidos, seu modelo foi criticado, principalmente em relação à noção de free lands, as denominadas terras livres do Great Western. Entretanto, existe um legado de ideias, principalmente pela proposta de uma nova concepção de fronteira, ou seja “(...) ele abandonava a idéia de uma fronteira fixa, como a européia, demarcada por uma grande densidade populacional e linhas fortificadas, e introduzia a noção de uma 
fronteira processual, isto é, em constante movimento, do Atlântico ao Pacífico" (AVILA, 2005, p. 193).

Ora, compreender as nações e o estabelecimento de fronteiras perpassa analisa-las como regiões, construídas e reconstruídas nos jogos entre prática, representação e apropriação, e nos sentidos atribuídos por Roger Chartier, jogos que traduzem as lutas do mundo em um mundo como representação (CHARTIER, 1991, p. 178). Sendo assim, a geografia imaginativa e seus constructos de efeitos palpáveis (SAID, 1990, p. 23) produzida por Turner engendrou a constituição de uma identidade nacional, e foi concomitante ao estabelecimento de sistemas simbólicos de representação, que delimitam fronteiras e classificam quem está dentro e quem está fora, pois a "representação atua simbolicamente para classificar o mundo e nossas relações no seu interior" (WOODWARD, 2000, p. 8).

Neste sentido, cabe notar a finalização do texto: “And now, four centuries from the discovery of America, at the end of a hundred years of life under the Constitution, the frontier has gone, and with its going has closed the first period of American history" (TURNER, 1893, p. 16). Turner utiliza como referência temporal a chegada dos europeus à América, bem como a constituição norte-americana, numa ideia de progresso contínuo, no qual sua geração representava o maior momento daquela história. Aquela fronteira se foi, e com ela se encerrou aquela a primeira fase da história dos Estados Unidos, ladrilhando o que estaria por vir. Suas conclusões engendraram uma ligação, legitimada por sua narrativa da história, entre o expansionismo territorial e o nacionalismo norte-americano como um destino, iniciado no Oeste, mas por realizar no resto do mundo. Se aquela fronteira se fechou, outras ficaram (ou foram) abertas pelos Estados Unidos no decorrer do século XX.

\section{As Fronteira Guaranis}

Em 1939, o jurista cearense José de Melo e Silva publicou um livro chamado Fronteiras Guaranis, sobre a porção meridional de Mato Grosso, na fronteira entre Brasil e Paraguai. O texto foi escrito durante o Estado Novo (1937-1945), governo autoritário de Getúlio Vargas que lançou projetos de censura e controle de ideias e espaços. Dentre eles, constava a Marcha para Oeste, que incluía a "colonização" e criação de colônias agrícolas nos "vazios" do Oeste brasileiro (LENHARO, 1986, p. 14). Entusiasmado com tal projeto, Melo e Silva buscou esquadrinhar aquela fronteira sob seu olhar nacionalista e católico, lançando pareceres sobre os potenciais econômicos subaproveitados, problemas e possibilidades de futuro. 
Para o autor, "É um Brasil à parte a fronteira meridional de Mato Grosso. Tudo lá é diferente: costumes, língua e, nalguns pontos, o próprio caráter do povo sofreu grande modificação" (MELO E SILVA, 2003, p. 78). É importante ressaltar que este é um olhar de estranhamento em relação a algo que não deveria ser diferente quando comparada ao modelo de civilização brasileira construído em centros urbanos como o Rio de Janeiro e São Paulo.. Contudo, apesar de ter sido publicado em São Paulo, o texto de Melo e Silva não teve um grande alcance no campo intelectual brasileiro no período de sua primeira escrita, embora tenha sido apropriado no processo posterior de transformação do Sul de Mato Grosso em Mato Grosso do Sul (FIUZA, 2017).

Para ele, deveria existir naquela fronteira um limite jurídico-político estabelecido, que deveria ser fixo, mas estava em movimento. Ao contrário do conceito de Turner, o Oeste brasileiro não acabava no Oceano Pacífico, mas em um outro Estado nacional: o Paraguai. Construir o Brasil naquele espaço significava imprimir representações de fronteira que estabeleciam a brasilidade a partir de um outro bem definido: o guarani paraguaio. Melo e Silva procurou analisa-los em viagens pelo que chamou de Lindes Guaranis, zona fronteiriça que incluía cidades como Porto Murtinho, Bela Vista ou Ponta Porã, por exemplo.

Em suas viagens, José de Melo e Silva viu estes indígenas outros multiplicarem-se nas fronteiras secas. Ao analisa-los, ressaltou com surpresa que eles reconheciam, ao passar a rua, que estavam entrando em outro país, pois "ao cruzarem a fronteira, dizem: Ahora vamos al Brazil" (MELO E SILVA, 2003, p. 185). No entanto, para Melo e Silva os próprios brasileiros ainda não faziam daquela fronteira um espaço nacional. Sem essa consciência formada, as consequências eram que aqueles estrangeiros "infiltram e até dominam costumes que não são nossos”. Identificar isso causava alarde no autor, que buscava auferir atenção para uma intervenção do Estado, afinal, "sem o cunho inconfundível de brasilidade não será nossa aquela civilização" (MELO E SILVA, 2003, p. 185).

O lado brasileiro da fronteira deveria ser dominado por brasileiros, e outras populações teriam que se sujeitar a esse limite político jurídico, fixado nos tratados e imaginado naquela paisagem. Era “justo, portanto, que construamos lá, naquela fronteira nossa, uma civilização que reflita o progresso, a cultura, os encantos, as maravilhas e a civilização mesma do Brasil", e conduzida por braços nacionais, pois "a sublime e delicada missão de construir a civilização da fronteira deve ser cometida preferentemente ao brasileiro" (MELO E SILVA, 2003, p. 185). A elevada missão de cunho patriótico realizavase na medida em que o Brasil se projetava sobre o outro paraguaio e fazia valer sua posição naquele espaço. Contudo: 
Os guaranis paraguaios não encontram obstáculos em transpor as nossas fronteiras, que são francamente abertas e abandonadas. (...) Vivem em nossa pátria como em sua própria terra. Talvez até se compenetrem de que sua casa é todo o continente sul-americano (MELO E SILVA, 2003, p. 81, grifo nosso).

A condição da fronteira guarani era que estava aberta e em movimento, mas, não deveria estar, porque além disso estava também abandonada pelo Estado brasileiro. Melo e Silva se colocava como alguém de fora, um cearense que estava naquele lugar com uma missão patriótica. Isso o fazia indignar-se com as pessoas que viviam na fronteira e não percebiam o mesmo que ele: "O representante guarani, que transpôs clandestinamente, prescindindo de qualquer formalidade, as suas divisas nacionais, penetrou igualmente no Brasil, sem observância de nossos ritos ministeriais. E na fronteira ninguém percebeu isso" (MELO E SILVA, 2003, p. 72). A clandestinidade seria apenas mais uma das transgressões apontadas por Melo e Silva como características daqueles indígenas.

Esse movimento de estrangeiros transgressores e que ainda por cima vem do Leste subverte a lógica de marchar para o Oeste, alarmando o autor. Isso porque o elemento guarani não era, nem de longe, considerado o trabalhador ideal para a fronteira. Melo e Silva os via como indisciplinados, alheios ao trabalho agrícola e que preferiam cantar e tocar músicas do que o trabalho contínuo. Irônico e ácido em vários momentos do texto, diz que "Seriam outras as condições da fronteira e de modo especial da baixada sulina, se machados, foices e enxadas tivessem aceitação na razão de um décimo das sanfonas, violões, violinos e bandolins que lá se vendem" (MELO E SILVA, 2003, p. 84).

Tal como em Turner, o indígena também aparece em Fronteiras Guaranis (1939) como uma ameaça, embora ameaças muito mais relacionadas ao contato cotidiano do que ao medo do contato violento, como nos assaltos às zonas de settlement no Indian Country descrito por Turner. Contudo, Melo e Silva não percebia mobilização para modificar aquela situação. As atitudes deveriam ser urgentes e construídas por vias alternativas de afirmação do que a violência direta. Para ele, "nacionalizar a fronteira não significa banir de lá o Guarani”, pois, "tamanha é a nossa afinidade com esse povo, tais são os laços que nos vinculam, que seria um absurdo a pretensão de afastar da fronteira o elemento paraguaio" (MELO E SILVA, 2003, p. 185).

E ainda acrescentou: "É verdade que no correr de todas as páginas destes livros temos assinalado as suas qualidades negativas, como agricultor". Porém, ressalta que sendo "o 
paraguaio um homem de grande resistência física e excessivamente corajoso, é de crer-se que ele se adapte a qualquer gênero de trabalho, e que será tão bom agricultor como qualquer outro" (MELO E SILVA, 2003, p. 185). Apesar de estar em uma situação perigosa, encarada de forma normal por aquelas pessoas que lá moravam, Melo e Silva vislumbrava possibilidades de torna-los brasileiros autênticos. O avanço nacional sobre aquela fronteira significava cultivá-la e estabelecer vias de comunicação para que o comércio fluísse de forma natural, domando o indígena, como se este pertencesse à natureza e impedisse o progresso e a civilização almejados pelo autor.

Para que houvesse esta transformação, seriam necessários três elementos principais: a educação, a lição do exemplo (do trabalho agrícola e da religião cristã) e o caldeamento das raças. Ou seja, a permanência do guarani na fronteira nacional deveria estar condicionada à entrega de seus filhos para a educação brasileira: "Ele, porém, deve acatar esse nosso desejo de que os seus filhos nascidos no Brasil sejam educados à moda brasileira, submetendo-se integralmente à nossa civilização" (MELO E SILVA, 2003, p. 185).

Além disso, essa transformação seria acelerada "no dia em que uma onda de nordestinos lá se fixe, rasgando os campos da fronteira. Falta-lhes apenas a lição do exemplo" (MELO E SILVA, 2003, p. 186). A religião e a educação a serviço de constituir identidades nacionais e (re)territorializar linhas de fronteira. Contudo, o grande condutor seria o Estado, personificado em Getúlio Vargas, ao mesmo tempo reverenciado e indiretamente cobrado para levar a cabo aquela missão, na qual seria:

(...) necessário que se dê a fusão com os estrangeiros que lá se encontram, e que desta amálgama resulte o predomínio dos nossos costumes, o império da civilização nacional. Sem que se introduza ali um grande volume de brasileiros fortes, de reconhecida persistência na observância de seus hábitos e também de resistência física experimentada no trabalho, a nacionalização daquele pedaço de território pátrio não se realizará e não irá além de um jogo de palavras (MELO E SILVA, 2003, p. 185).

Ao dominar pelo número, a fronteira era brasileira por direito, mas culturalmente guarani (CENTENO, 2007, p. 173). E um guarani paraguaio, indesejável, que ameaçava o império da civilização nacional. Ao construir essa representação de fronteira sobre uma terra tratada como sertão incógnito, também podemos considera-la uma fronteira aberta (MACHADO, 2012, p. 37). Ela também estava em constante movimento, embora devesse ser fixada, e só seria realizada na medida em que a mão forte do estado nacional brasileiro chegasse até lá. 
Transformar aquelas pessoas em brasileiros visava solidificar fronteiras vivas, impermeáveis ao elemento estrangeiro indesejável, mas buscar o amálgama da civilização brasileira construída na costa do Atlântico, e ansiada na fronteira Oeste. Só então, os potenciais econômicos almejados seriam realizados. Novamente, notamos uma retórica de futuro e progresso irrealizado, bem como a projeção do Brasil sobre os vizinhos sulamericanos como modelo de civilização para populações indígenas e Estados nacionais.

\section{Considerações Finais}

Pensar estes distintos conceitos de fronteira, com dois contextos históricos específicos nos Estados Unidos da década de 1890 e o Brasil da década de 1930, é pensa-los enquanto símbolos negociáveis da constituição de regiões. Isso significa que não são diametralmente opostos nem plenamente iguais. Pelo contrário, é possível perceber continuidades discursivas para problemas de território e nação, e constituíram nas suas especificidades as relações de poder que delimitaram suas fronteiras. O próprio percurso de constituição destes conceitos de fronteira fundamentaram projeto políticos de expansão de Estados em distintos tempos e espaços na América, englobando similaridade e diferença, e se pensados a partir da ideia de apropriação, podem não ser pensados apenas como oposições binárias ou totalidades permanentemente coesas e coerentes (HALL, 1996, p. 70).

Assim, pode-se dizer que Turner idealizou a nação norte-americana realizada por seu progresso rumo ao Oeste, considerando a fronteira aberta e local onde se realizava os Estados Unidos da América rumo ao Oceano Pacífico. A fronteira, o Oeste e a nação, espaços construídos por anônimos do passado que projetaram um futuro de esperanças, e tiveram aquela terra como destino inexorável, não apenas de um indivíduo ou família, mas do coletivo nacional. Além disso, funcionaram como fonte de legitimidade para o nacionalismo e o expansionismo industrial e militar norte-americano.

Na América do Sul, a ideia de realizar um estado-nação na fronteira Oeste também foi desenvolvida no Brasil durante os séculos XIX e XX, sob auspícios de projetos regionais de (re)ocupação (FREITAG, 2007, p. 17); e retomada com especial atenção no período do governo Getúlio Vargas, especialmente no Estado Novo (1937-1945), como nos escritos de José de Melo e Silva. O autor visualizava uma fronteira que na prática era marcada pela ausência do Estado e da nação, no qual o primeiro deveria ser o responsável por forjar o segundo. Além do projeto da Marcha para o Oeste, influenciou na escrita dos textos uma visão católica e liberal conservadora, que perpassou também a admiração de Melo e Silva 
com a postura imperialista norte-americana, o que ele chamava de yankismo, imaginando caminhos parecidos para o que chamava de progresso da civilização brasileira.

Assim, Turner visualizava no Oeste uma terra livre, uma fronteira aberta até o Oceano, e cujo constante movimento era a catarse nacional. Já Melo e Silva também via uma fronteira em constante movimento pelos fluxos migratórios guaranis/paraguaios, mas, isso o preocupava uma vez que defendia fixar e regulamentar as fronteiras em relação ao outro Estado nacional. Assim, ambos legitimavam uma geografia imaginária baseada no desenvolvimentismo econômico e na (re)territorialização de povos e espaços. Ressalta-se a importância de estudar diferentes autores e contextos nacionais diversos, procurando perceber regularidades discursivas, rupturas e continuidades. Seja nas difundidas teses de Turner, ou no pequeno alcance do trabalho de Melo e Silva, ambas as perspectivas de fronteira trabalhadas, mesmo em suas diferenças, legitimam constructos de Estado, nação e identidades.

Assim, pensar os conceitos de fronteiras utilizados por diferentes intelectuais americanos em perspectivas dialógicas e transnacionais, permite suscitar novas questões. Existiram movimentos Oeste-Leste? Como foram pensados? Quais as possiblidades de história comparada entre movimentos de interiorização na fronteira sul-americana com o Brasil? Como textos e autores trabalharam a ideia de ciência e de estado nacional na constituição de fronteiras sul-americanas nos séculos XIX-XX? Quais usos do passado fizeram nessas dinâmicas? Quais conceitos foram utilizados, apropriados ou desenvolvidos para pensar as fronteiras nacionais na América Latina? A partir desta pesquisa, essas e várias outras questões surgem como lacunas e possibilidades para pensar pesquisas, temas e autores transnacionais na construção de fronteiras.

\section{Referências}

ALBUQUERQUE JR, Durval Muñiz. O Objeto em Fuga: algumas reflexões em torno do conceito de região. Fronteiras - Revista de História da UFGD. Dourados, v. 10, n. 17. p. 5567, 2008.

ANDERSON, Benedict. Comunidades imaginadas. Reflexões sobre a origem e a expansão do nacionalismo. Lisboa: Edições 70, 1991.

ÁVILA, Arthur Lima de. O Significado da História. História. São Paulo, v. 24, n. 1, p. 191 223, 2005.

. E da fronteira veio um pioneiro...: a frontier thesis de Frederick Jackson Turner (1861-1932). 2006. 175 f. Dissertação (Mestrado em História), Programa de Pós-Graduação em História, Universidade Federal do Rio Grande do Sul, Porto Alegre. 
BOURDIEU. O Poder Simbólico. Trad. Fernando Tomaz. 14 Ed. Rio de Janeiro: Bertrand Brasil, 2010.

CENTENO, Carla Villamaina. Educação e Fronteira com o Paraguai na historiografia matogrossense (1870-1950). 2007. 257 f. Tese [Doutorado em Educação]. Faculdade de Educação, Universidade Estadual de Campinas, Campinas.

CHARTIER, Roger. O mundo como representação. In: Estudos Avançados - Universidade de São Paulo. São Paulo, v. 5, n. 11, p. 173-191, 1991.

FREITAG, Liliane da Costa. Extremo-Oeste Paranaense: História Territorial, Região, Identidade e (Re)Ocupação. Tese [Doutorado em História]. Franca: UNESP, 2007.

FIUZA, Wagner Henrique Neres. Do Sul de Mato Grosso ao Mato Grosso do Sul: região e historiografia em torno da obra de José de Melo e Silva. 2017. 255f. Dissertação de Mestrado [História]. Universidade Estadual do Centro-Oeste. Irati.

HALL, Stuart. Identidade cultural e diáspora. Revista do Patrimônio Histórico e Artístico Nacional, n. 24, 1996, p. 68-75.

LENHARO, Alcir. Sacralização da Política. Campinas: Papirus, 1986.

MACHADO, Marina Monteiro. Entre Fronteiras: posses e terras indígenas nos sertões (Rio de Janeiro, 1790-1824). Guarapuava: UNICENTRO, 2012.

SAID, Edward W. Orientalismo: O Oriente como invenção do Ocidente. São Paulo: Cia. das Letras, 1990.

SILVA, José de Melo e. Fronteiras Guaranis. 2 ed. Campo Grande: IHGMS, 2003.

TURNER, Frederick Jackson. The Significance of the frontier in American History. Chicago: Wisconsin Journal, 1893.

WOODWARD, Kathryn. Identidade e diferença: uma introdução teórica e conceitual. In: SILVA, Tomaz Tadeu da (Org); HALL, Stuart; WOODWARD, Kathryn. Identidade $e$ diferença: a perspectiva dos estudos culturais. $4^{a}$. Ed. Petrópolis: Vozes, 2000. P. 7-72. 